\section{JSCN T \\ Journal of Sustainable Construction \\ Materials and Technologies}

Journal of Sustainable

Construction Materials

and Technologies

J Sustain. Construct. Mater. Technol. 1(1) (2016) 36-45

www.eds.yildiz.edu.tr/jscmt

\title{
LISI - the House - Living Inspired by Sustainable Innovation
}

\author{
DI Dr. Karin Stieldorf* \\ Sustainable Planning and Design Group, Department for Architecture and Design \\ Faculty for Architecture and Urban Planning, Vienna University of Technology \\ Gusshausstr.30, 1040 Vienna, Austria. E-mail: stieldorf@hlarch.tuwien.ac.at
}

Received January 3, 2015, accepted February 20, 2016

\begin{abstract}
LISI was the competition entry of Team Austria for Solar Decathlon 2013 in Irvine / Los Angeles / California and overall winner of the competition. The paper describes the project aims and objectives, the house self, its key innovations, economic aspects and market potential.
\end{abstract}

Keywords: Solar Decathlon 2013, competition, sustainable architecture, innovation

\section{Introduction - About "LISI - the house"}

"LISI - the house" (Living Inspired by Sustainable Innovation) has been developed and constructed as an exemplary, allover excellent residential prototype - it is innovative and experimental, but also cost-low, energy efficient, ecologic and attractive. Many innovations in the field of sustainability come from architects, but rarely companies are involved as engaged and intensively as in this showcase. This project was meant to contribute to the endeavor "sustainability", as well as to the transatlantic exchange of innovative ideas and technologies between Europe and the US.

LISI was the overall winner of the "Solar Decathlon" (SD) of the United States of America in 2013. The SD is the most important competition in solar design between universities worldwide. It has been founded to encourage an essential shift in public awareness towards the need for sustainably built and occupied environments. In particular, the competition is to motivate students for solar and sustainable construction and to prepare them for acting responsibly in their future professional life. The competition ended in California with a two-week public final round of the best 20 teams out of 150 participating university teams. There they competed against each other with their solar-powered houses.

Participation in competitions has proven to be a very effective educational tool. It is exciting for students to implement a planning / construct a building in a 1:1 scale, guided and accompanied by teachers and other students of the technological and scientific field. In the course of the competition a real construction process is conducted: from initial to detailed design, from tender to execution, from artisanal activity to communication all is included. Further, the research and development process takes place in collaboration with companies. Conversely, companies benefit from groups of young and dedicated students developing new and innovative technical concepts for them. The dialogue was fruitful, pleasurable and successful.

\section{Description of The Competition Project "LISI - The house"}

\subsection{Project Aims \& Objectives}

The project "LISI" focused to achieve the following goals:

- "Energy Plus" standard by embedding an effectively optimized set of advanced technology components.

- Economical construction, easy to assemble and disassemble by using pre-fabricated wooden components that are small, lightweight and eco-friendly and sufficiently durable for repeated transportation and re-assembly.

\footnotetext{
${ }^{*}$ Corresponding author: DI Dr. Karin Stieldorf

E-mail address: stieldorf@h1arch.tuwien.ac.at
}

https://doi.org/10.29187/jscmt.2017.4 
- Functional flexibility by means of an adaptable design concept to meet the changing needs of potentials occupants.

- Variably additive building units that can be scaled to denser urban structures to reduce land use and commuting distances between workplace, social centers, and home.

- Aesthetically satisfying and healthy environment by offering moments of "surprise and delight" in architectural detail, daylight and sunshine in winter, agreeable temperatures and shading in summer, as well as high indoor air quality year-round.

- Multi-dimensional integration of building levels through a holistic design approach in trans-disciplinary collaboration between architects and civil engineers, electrical and mechanical engineers, physicists and artists, product and media designers, as well as specialists for timber construction, lighting design, accessibility and safety, and other contributing disciplines.

- Excellent Building Certificates were provided according to location and regionally applicable standards (ÖGNB-Gold, DGNB-Gold, LEED-Platinum).

- Multidisciplinary Team-Work by collaboration of architects and (also scientific) experts in earliest design stages to provide the skills for designing, planning, and building the house. Trans-disciplinary collaboration between faculties and institutes was the guiding principle in the development of the competition, in teaching and in research work.

- Building Transportation: All building components were fully pre-fabricated and prepared for shipment to the Solar Decathlon 2013 site from Vienna. Six high-cube containers (hard-top/open) are sufficient for stowing the entire disassembled house, including its mechanical and electrical system components, as no single component exceeded the clearance dimensions of a standard freight container (length 40', height 9'6"). By avoiding oversize cargo formats, economical shipping rates were feasible. High transportation costs would have made the participation of Team Austria impossible.

\subsection{Description of House}

The LISI-house is divided into three primary zones: service core, living area, and adjacent patios. The spacious living area is the center of the house and provides room for a variety of activities. Sliding glass façade components open up to the northern and southern patios. Depending on the residents' climatic and social needs, shading elements help LISI to close or open up to her surroundings. The service core - housing the bedroom, bathroom, and all essential technical equipment - serves as a private retreat. The synergy of modular timber construction and the use of renewable materials and energy systems create a sustainable and affordable house for a broad range of users and sites, see http://www.solardecathlon.at./?lang=en .

With intensifying urban populations come increasing demands for compact, affordable, yet energy-efficient and environmentally friendly housing solutions. Changing functional and mobility needs throughout household lifecycles call for flexible homes that can be adapted to meet the requirements of changing usage patterns and site locations. The LISI house was developed to meet these challenges. LISI's concept rests on three pillars: sustainable design, renewable energy, ecological materiality

- Sustainable Design

Designed around the base-case of two residents, LISI is an ecologic house that was developed in line with aesthetic principles for living in harmony with nature. Two patios structure the space and create a balance between interior and exterior, public and semi-public spaces, affording enough daylight and cross-ventilation. Flexible architectural layers create adaptable boundaries between indoor, semi-indoor, semi-outdoor, and public outdoor spaces, which can be easily and seamlessly configured to meet the residents' preferences. Automatically controlled shading elements also help avoid overheating on hot, sunny days and significantly reduce cooling loads.

- Renewable Energies

LISI has been developed following fundamental principles of ecological, sustainable, and energy-efficient building design. The first priority is to minimize energy and water consumption, and thus keep our house's resource demand to a minimum. In order for LISI to generate the energy still needed for heating, cooling, and electricity to power appliances and automation systems, passive solar strategies are employed in coordination with the performance of active system components. A photovoltaic array integrated in the outer shell provides enough electrical energy to meet the entire house's operational energy needs. Our concept is demonstrated in an experimental prototype for sustainable living that supplies all of its own energy through entirely renewable resources. LISI's "micro-ecology" is carefully designed and engineered to provide the desired energy and comfort for a healthy lifestyle with minimal negative impact on the environment. Beyond meeting the basic demands of a contemporary lifestyle, the goals met by LISI's technical systems incorporate the following three criteria that are pivotal in creating a building fit for the future and for any location: 
Efficiency and life cycle costs: all employed components not only individually represent the most efficient products currently available, but these are also configured in integrated systems, which together work as one efficient body. In addition, special care was taken in the choice of the individual system components regarding their impact on the overall life cycle balance.

Cost effectiveness and availability: without a doubt, the factors of market availability and innovativeness of system components may be seen as contradicting criteria. But we firmly believe that the best products currently available have reached a stage of maturity that does not leave significant room for further efficiency gains in regard to the newest innovations in this sector. The actual distribution and wide-spread market presence of houses like LISI may, therefore, be regarded as the most pressing goal that Team Austria was tackling in the competition. As a multiplier, such projects as the LISI house shall serve to demonstrate the economic viability of investing in such living styles of new, sustainable home environments.

Plug \& Play: LISI's energy system strives to combine simplicity and user-friendliness with efficiency and ingenuity. On the one hand, home owners need an interactive system in order to operate their inherently complex living environment on a day-to-day basis; on the other hand, they should not be expected to fully understand the technological underpinnings of their home's energy system in order to simply live there. The system must therefore be easy to operate and to maintain. This means that the installers of system components absolutely had to understand the overall energy system that their components are a part of, as well as the influence of their components on the overall system. They had to be able to design and correctly size LISI's system, and feel safely competent with operation modes and control strategies.

- Ecological materiality

The third pillar of our concept is an optimized use of resources at the material level. The LISI house consists almost entirely of renewable and eco-friendly materials, whereby the base material for construction and thermal insulation is timber. Besides being carbon-neutral, lightweight and easy to transport as a construction material, the use of wood-based materials in housing has a positive effect on the indoor climate and the living comfort. Following the ideal of using consumable resources as responsibly as feasible, the LISI-house is designed such that all parts of a tree - from the heartwood to the bark - are utilized according to their best applicable properties. This means that wood-based materials are used not only as a construction material, but also for finishing (wall and ceiling cladding, flooring), as well as furnishing. Thus the base material of wood is truly present and can be sensed in all its facets.

\section{Unique House Features}

"LISI - the house" is divided into three primary zones: service core, living area, and adjacent patios, which are interfaced by circulation zones. The interior is easily accessible via a ramp, which is enveloped by the outermost textile façade layer. The spacious and flexible living area is at the center of the house and provides ample space for various activities. All storage areas are integrated into the walls, thus freeing up the primary indoor space and affording greater flexibility in its functional transformation. Large sliding glass elements open up to the patios towards both the north and the south of the central living area. Depending on climatic and social preferences, the residents can adjust the outermost façade and other shading elements to completely close or open up their home to the exterior environment surrounding the house. This means that LISI can transform from a protective cocoon to an extrovertly open house for friends and neighbors - or anything in between. The walnut colored service core contains the bedroom, bathroom, and all technical equipment. It serves as a private retreat and provides a contrast to the open living area. Visual connections through the architectural layers and spatial transitions through levels of privacy create a surprisingly intense variety of ambiences within a relatively small building space. The choice of materials underscores the house's character and strengthens emotional identification with it. Wood is the dominant material used for construction, as well as for the exterior and interior design. It can be felt everywhere in the house and provides an outstanding quality of fresh air indoors. What make LISI especially unique is the central living area, which can be extended by opening sliding facade elements across their entirety to incorporate adjoining patios toward the north and south. This affords LISI's residents private outdoor areas and the direct contact to nature within the limited floor space of their own home. Variable architectural layers enable the transparency of the house to be modified according to the desired level of privacy. This ranges from an isolated cocoon to an open and communal gathering place. 

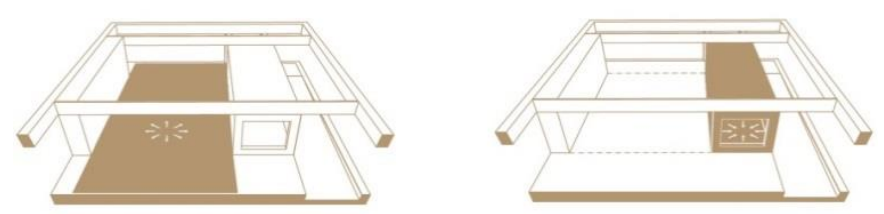

Figure 1. Extroverted living area and introverted retreat area, connected by sliding doors

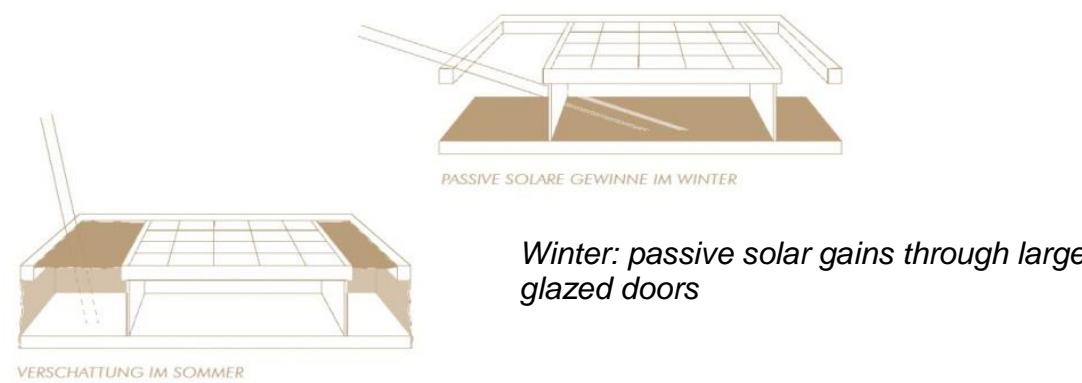

Summer: shading provided by automated sails

Figure 2. Seasonal Adaption

It is not only this spatial flexibility which sets LISI apart from conventional houses. Another key element is the geographical flexibility it offers. With merely slight adjustments to the thermal insulation, LISI will function efficiently in almost all corners of the world. The dimensions of the individual modules are tailored to the size of international freight containers and make LISI a flexible home for nearly everywhere on planet Earth.

\subsection{Development of a new timber construction system}

Austria is well known for its advanced timber engineering and wood-based construction. As a "sub-project" within the framework of the competition, students of the University of Applied Sciences Salzburg had the opportunity to collaborate with civil engineers, architects, and the timber industry on the development of a new

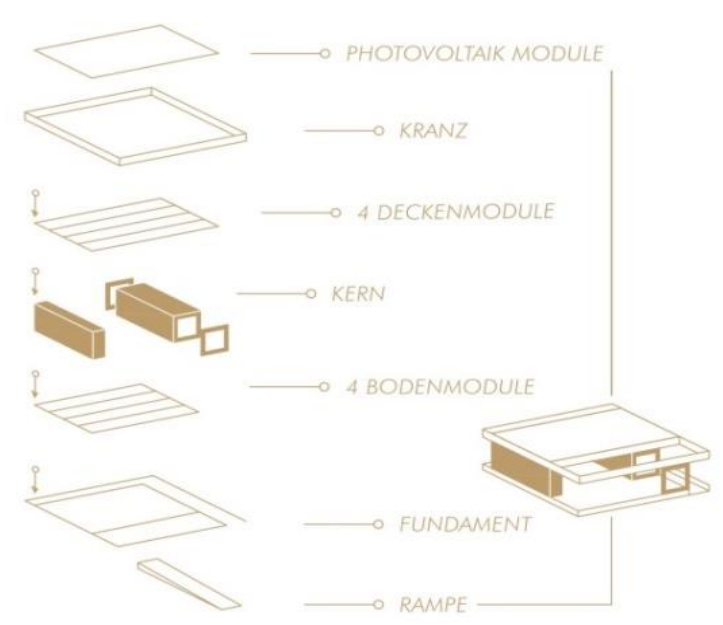
construction system of modular components (with Weissenseer company).

\section{MODULARITY}

○ Pre-fabricated

- modular system

○ light wood-construction

- customized for international shipping containers

- improved structural connections for multiple assembly and disassembly of the building, enabling re-use and clean down-cycling

Figure 3. Specifics of new timber construction system 


\section{Key Innovations}

\subsection{Contribution to Technological Progress}

Mechanical systems

LISI is a plus-energy home generating all its required energy electrically with a roof-mounted photovoltaic array. Thus excess energy, which is not immediately needed to operate the house, can be fed into the power-supply grid or stored to power electric vehicles. The supply of cold and hot water for space heating and cooling, as well as for domestic hot water relies on two air-water heat pumps. Comfortable and healthy air conditions are provided by an energy recovery ventilation unit, which acts as a heat and humidity exchanger between used exhausted air and fresh intake air. LISI's energy system is also a carefully engineered combination of technological components. A multifunctional floor system (developed with company ClimaLevel), regulates the entire building's climate using water, air, and active cubic capacity. It efficiently provides heating, cooling, and fresh air to create a consistently comfortable indoor climate. This is new for small residential buildings. Additionally, an innovative shower tray, which recovers otherwise lost thermal energy from drain water through a heat exchanger, significantly reduces the net energy consumption caused by showering and related hot-water needs for daily hygiene.

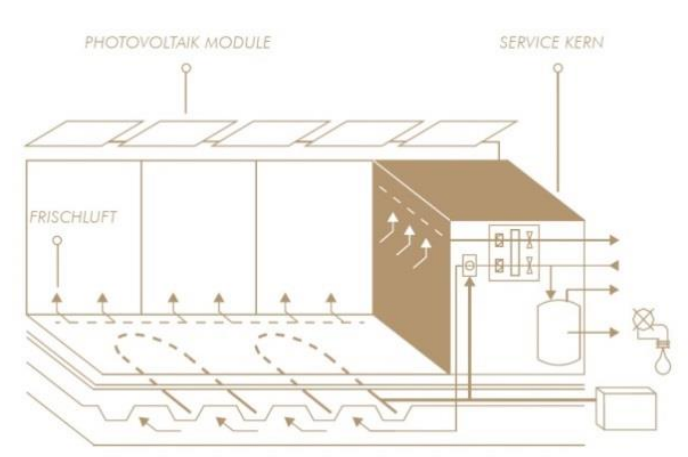

Figure 4. Building services system
- Total energy from photovoltaic system integrated in the roof

o hot and cold water for space heating and cooling through 2 air-water heat pumps

○ Ventilation module with integrated heat and moisture exchanger

○ building heated, cooled and ventilated by multifunctional floor

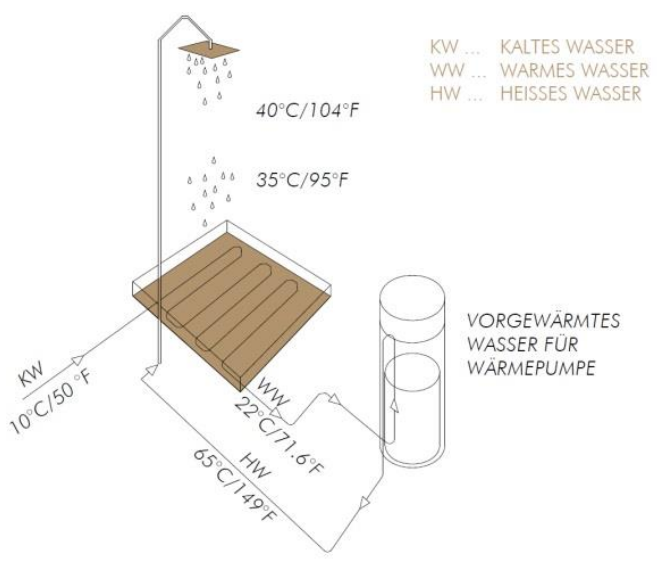

- Heat of waste water is recovered by innovative shower tray with integrated heat

- Reduces energy demand in the shower

Figure 5. Energy saving shower

Context-sensitive smart-home controls

The operations of all technical components are ideally coordinated thanks to LISI's smart home system, which offers innovative human computer interaction (HCI) and interaction design concepts for context-aware, multi-modal home control and energy monitoring. Automatically bringing task light to the kitchen counter when cooking, watching TV by simply settling in on the couch, eating dinner with your favorite mood music playing automatically, switching off all lights and energy consuming devices when going to bed - such conveniences are 
all possible, even without a remote, when residents themselves act as the interface. The LISI house prototype uses real-time sensors and actuators in order to aggregate and analyze (and reason behavioral conclusions from) data such as the energy consumption of each individual appliance in the house over the course of the day. An energy profiling and control unit processes the collected data and estimates future energy consumption and savings potentials. The technology behind this "LISI Core" acts as a centralized hub for all energy-consuming systems of house operation. It allows the control of almost every device function, such as turning on the TV, as well as combined house scenario modes without the need to explicitly control through a remote. Instead, the control of devices and appliances is implicitly based on operational context data from the household and its inhabitants. In short, LISI offers an interactive system as an interface to all house operation data that enables:

- ambient visualization displays, e.g., live-data streams on our website;

- a tablet interface for advanced visualization and control by residents;

- small, ubiquitous "LISI Flake" modules that monitor activity in the house to establish convenience principles of implicit control rules.

\subsection{Contribution to Ecological Progress}

One of the main themes of the project was to use "all of the tree". As no use for wood-based waste material had been explored, bark or saw-dust has been burnt in the last years neglecting the obvious qualities and potentials of the material. Teachers and students from FH Salzburg focused on changing the handling of these materials and developed new methods to make ecologic use of them. They worked out a complex craft process for producing wall coverings which were used for the "intimate" part of the competition project "LISI" - the sleeping room and the bathroom. The production process is still worked on in order to make it simpler and less time-consuming. As an additional "sub-project" students had the opportunity to collaborate with the Organoid company and made furniture from bark and from saw-dust. The newly developed method of production is promising - the chairs will be produced and sold in the future, see http://www.solardecathlon.at/lisi-woodwork/?lang=de

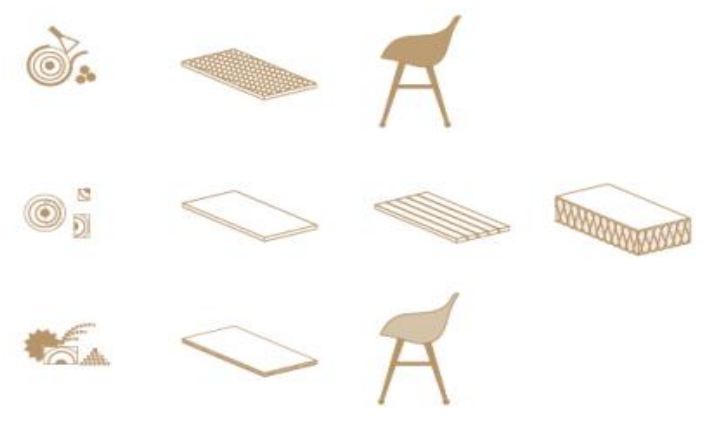

Figure 6. All from the tree is used:

○ bark as a wall covering

- solid wood for construction and surfaces

- sawdust for furniture (chairs)

$\circ$ wood fiber for insulation

Development of sliding doors (with company Josko) and insulating shutters

The central design idea of the house was the sliding doors to the two patios. If they are open, it gives an approximately $150 \mathrm{~m}^{2}$ large living room that can be played differently depending on weather and use. The system of sliding doors was developed as a supporting technological research in preparation for the competition and is now successfully sold by Josko. In addition, as part of a thesis, the development of insulating sliding shutters for the location of Vienna has begun. This development is also carried out in collaboration with a company and is progressing well. Both systems together form a new architectural solution that is perfectly adapted to the weather in Austria and is urgently needed in other construction areas like office buildings. Large transparent openings to the north are a common week point in the building envelope and can thus be improved significantly.

\subsection{Uniqueness of the developed concept}

The holistic concept of "LISI the house" is unique for several reasons:

- Pure timber ( $97 \%$ of construction; aesthetically expressed inside and outside),

- Simple, but efficient building technology,

- The low-cost photovoltaic system supplies the house totally; in combination with the two installed heat pumps it makes its users nearly independent from the public grids. 


\section{SCIENTIFIC APPROACH AND OUTCOME}

\subsection{Scientific quality of project results}

From a scientific perspective, the focus of the project was the precise interpretation of the building for the relevant climates (Irvine, Vienna) and the preliminary simulation of the thermal performance of the building for different usage scenarios. The results served to accompany the project development of the energy concept, the selection of building construction (among other criteria) and the design of the structure (ratio opaque to transparent components, orientation of the glass surfaces, etc.).

Determining requirements for this were:

- carefully creating the climatic data (Irvine, Vienna) as a basis for all simulation tools used (which cannot

be regarded as a trivial challenge as reliable measuring data is not available frequently)

- the description of potential usage scenarios in the smallest number possible with regard to the predetermined range of the target temperature of $22^{\circ}-24^{\circ} \mathrm{C}$

An exemplary challenge was to reduce the air temperature in the house to the required level rapidly after having risen during the visiting hours (open doors, body heat from visitors). The outcome was decisive for the selection of the components of the home automation system and operation. These tasks were successfully solved by simulation. In the competition, many points for the victory could be achieved due to the positive assessment of the jury.

\begin{tabular}{|c|c|c|c|c|}
\hline Scenario & Location & Setup & Start time & End time \\
\hline SD & Irvine, standard & SD & Oct, $1^{\text {st }}$ & Oct, $31^{\text {st }}$ \\
\hline SD, bleak & Irvine, bleak & SD & Oct, $1^{\text {st }}$ & Oct, $31^{\text {st }}$ \\
\hline SD, extreme & Irvine, extreme & SD & Oct, $1^{\text {st }}$ & Oct, $31^{\text {st }}$ \\
\hline IRV & Irvine & Standard & Jan, 1 st & Dec, $31^{\text {st }}$ \\
\hline VIE & Vienna & Standard & Jan, 1 st & Dec, $31^{\text {st }}$ \\
\hline
\end{tabular}

Figure 7. Scenarios to be investigated fort the operation in Irvine

\subsection{Results of „LISI - the house” in the Solar Decathlon Competition}

"LISI-the house" performed best of all participating houses in the sub-contest "Energy Balance" [Fig.8], and can be expected to operate well when having returned to Austria. As scientific project outcome the exemplary development process is most important. The design and implementation of the house were accompanied by way of example with scientific methods. This resulted in a climatically perfectly adapted design and allowed to operate the house properly. The outcome of the project is documented in the web in detail and presents a wellobserved step towards climate-friendly design strategies. With the increase of design and construction activities of architects and engineers abroad and the strengthening of construction companies in developing countries solid knowledge in this area of work is becoming increasingly important for the global environment.

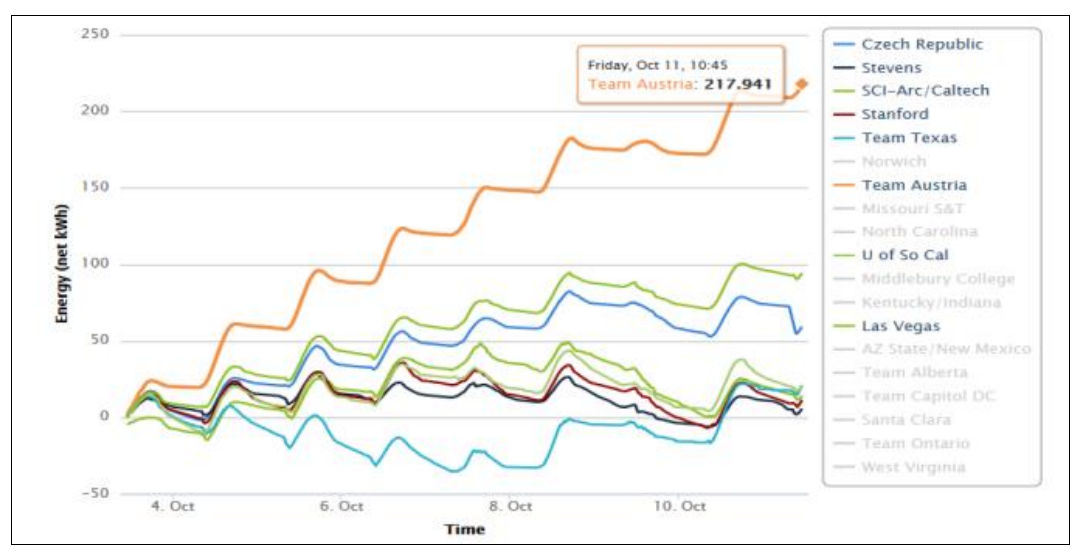

Figure 8. Thermal performance of the competing Solar Decathlon homes of the 2013 competition 


\section{Economic Aspects}

In order to participate in the Solar Decathlon competition, it was necessary to search firms as partners at an early stage that accompanied the competing team and were ready to act as sponsors of the construction material. Overall, we gained about 170 sponsors for supporting our participation in the Solar Decathlon and the construction of the house (http://www.solardecathlon.at/sponsors/?lang=en).

\subsection{The economic importance of Timber Construction in Austria}

"LISI - the house" consists of 97\% wood. Building with wood causes 58-71\% less greenhouse gases than other constructions and is particularly environmentally friendly. The timber industry is one of the most important employers of the 17 industries in Austria, but suffered a (small) decrease in the last year. The majority of enterprises are small and medium-sized (SMEs) and are in private hands. The industry is heavily in foreign trade with an export share of 66\%. Especially in rural areas, the wood industry (1400 companies and app. 27,000 employees) is a stable employer. Continuing education and training play a major role in the FH Salzburg - Kuchl is the center of education of the Austrian wood industry.

\subsection{Status of Implementation in the companies}

The main sponsors of "LISI-the house" have become business partners and are now involved in the production, construction, marketing and distribution of the house:

- The company Weissenseer Holz-System-Bau GmbH (40 employees; slogan: "Intelligent Building Skins") produces the house as a general contractor and has taken over the distribution. Weissenseer is also involved in the development of the timber system together with the FH Salzburg (serial / industrial production). The companies Weissenseer and Hasslacher produced and delivered the pontoons on which the house was mounted in summer before the reopening in the „Blaue Lagune“ (with students) and is now "swimming” in/on the lagoon. Currently floating houses represent an international trend. http://www.weissenseer.com/; http://weissenseer.com/uploads/media/Standart_lisi.pdf

- The company Josko Fenster \& Türen GmbH (850 employees; 10,5\% market share; 15,5 \% export share) manufactures and supplies the large glazed sliding doors. The newly developed sliding glass system was put in its segment.

http://www.solardecathlon.at/sponsors/principal-partner/; http://www.josko.at//upload/media/PA_SolarDecathlon_5722/PA_SolarDecathlon.pdf

- ClimaLevel (20 employees) manufactures and supplies components (multifunctional floor) for the smart home systems, which are incorporated by CleenSolair (16 employees).

http://www.solardecathlon.at/sponsors/premium-partner/

\subsection{Economic Relevance}

For Weissenseer the involvement in the development of LISI as a "principal partner" of Team Austria was a substantial investment in the future of the company. As Carinthian company the development of the Vienna Economic Area and the technological access to Vienna UT and FH Salzburg was important to it. Their primary objective is the creation of sustainable, energy-efficient, environmentally friendly and yet affordable living and working space. Research and development takes up a central place in their business. Josko_strives to become the technology leader in window-manufacturing in Austria and is therefore keen to strengthen its competitiveness. Weissenseer, Josko, ClimaLevel, CleenSolair and other companies are strongly involved in activities subsequent to the competition. There is a lively exchange, both in business as well as in relation to development of the joint product "LISI", its presentation and establishment in the market. Together with our new partner FH Joanneum University of Applied Sciences (Kapfenberg), marketing strategies are now being explored, designed and developed based on market analysis and searches done by the students of VUT and FH Joanneum.

\section{MARKET POTENTIAL}

\section{1. "LISI-the house" represented in the "Blaue Lagune"}


In the competition Solar Decathlon market potential was one of the major topics. "LISI - the house" was ranked second in this sub-task. This is best confirmed by qualifying LISI attractive enough to be presented now after the competition in the biggest and well-known exhibition area for prefabricated houses, the "Blaue Lagune". Around 100 exhibitors are on site, promoting their prefabricated houses of wood, brick or concrete blocks in a variety of architectural styles. They also offer expert advice on amenities and home financing. The "Blaue Lagune" is ranked second among the exhibition areas for pre-fab houses in Europe and competes with Hamburg for the first place. LISI has been re-built in summer and opened there on Oct., $2^{\text {nd }}$ by Minister Stöger. LISI now stands open to visitors during business hours. The opening of the house and the project itself were commented very positively in the media.
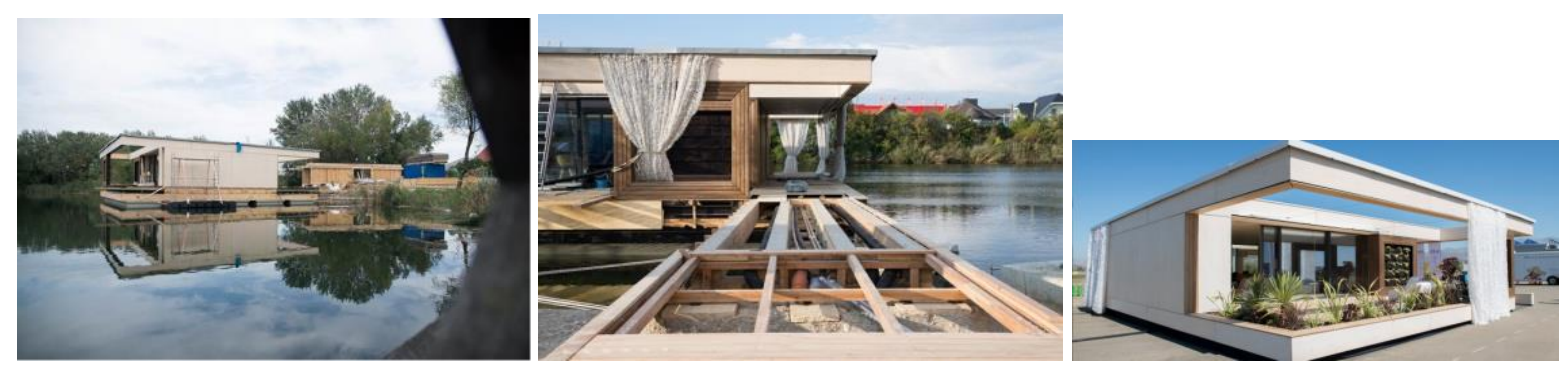

Figure 9. LISI-the house

\subsection{Relevance for industrial translation}

Our cooperating partner Weissenseer has already started with the distribution of the house. LISI's target group of potential residents is ecologically aware, intellectually agile, young at heart, and contemporary of mind. As a small prototype, the LISI house would serve well as the "start-up" residence or weekend home of a couple, but may also be used as the nucleus for communal living in broader concepts for residential development. It affords the space for real possibilities, making it: "A house for almost everyone, almost everywhere."

Two main applications have been identified within the project's development:

- $\quad$ LISI as a small allotment garden house for urban areas and nearby recreation areas

- $\quad$ LISI as a chalet for touristic developments

Vienna has set itself the task of consistently and continuously modernising the city in order to reduce energy consumption and emissions significantly without having to forego any aspects of consumption or mobility. Smart City Vienna stands for the "intelligent city"- intelligent and innovative solutions, responsible and sustainable use of resources.

LISI has been designed to meet the needs of today's generation: LISI is an aesthetically and functional appealing home, simple in its handling of devices by automated control and affordable. All the house's materials and equipment is state of the art, commercially available and affordable. An additional feature of the house that supports its concept is the herb garden fed by water collected from the roof.

For customers LISI is presented in three versions:

Type A - Basic version with all the design and technical equipment; completion by owner

Type B - Turnkey version, excluding furniture

Type C - Turnkey version, including furniture

Under these boundary conditions, it is particularly important that potential customers feel addressed by design and furnishing of the house, and that they recognize the sustainable setting of the design: Energy efficiency, ecoefficiency and the use and re-use of renewable materials and energy. The high flexibility of LISI in function and features ensures that the house adapts to a variety of situations, thus guaranteeing longevity.

\subsection{Commercial scalability of project results}

The competition "Solar Decathlon" has started in 2002 in the US, where it is held every 2 years, now already 6times. The SD Europe has launched in Madrid in 2010 and was held this year at Versailles / Paris. "LISI the House" is the first house to be used commercially. From interest of the companies in the house, it may be 
concluded, that LISI obviously and hopefully has a high market potential. The marketing was thought along early, since it was known that many previous projects are not used and not well maintained.

Obviously, this view has encouraged the orientation to the market. In addition, the faculty advisor has been active and known in this environment since long, and has had the practical implementation of the project in mind from the beginning. She can look back on a number of previous experiences.

\section{Relevance for the business location Austria}

"LISI-the house" was well received by all sides bestowed, especially internationally. This certainly has relevance for the pre-fabricated house market in Austria and its success, but also for the training location Austria when it comes to sustainable construction.

\section{TU ar.tuwien I Fakultät für Architektur und Raumplanung

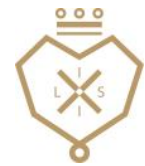

\section{Blaue Lagune} Building Intelligent Skins

Project:

- Faculty of Architecture and Planning (Vienna University of Technology)

- Weissenseer Holz-System-Bau GmbH

- Josko Fenster \& Türen GmbH

- Fertighauszentrum "Blaue Lagune"

\section{Project Leader:}

- DI Dr. Karin Stieldorf (Vienna University of Technology)

\section{Co-operating Institutions:}

- Vienna University of Technology

- University of Applied Sciences St.Pölten

- University of Applied Sciences Salzburg

- Austrian Institute of Technology 